\title{
A Study on Thai Taxi Drivers' Cross-cultural Communication Problems and Challenges
}

\author{
Thadphoothon, Janpha \\ Faculty of Art, Dhurakij Pundit University, Bangkok, Thailand \\ janphadpu@gmail.com
}

\begin{abstract}
This study investigates Thai taxi drivers' cross-cultural communication problems and challenges by synthesizing the research findings from two related studies: (1) a classroom investigation of Thai taxi drivers' communication challenges and (2) a study on Thai taxi drivers' English language competence (Thadphoothon, 2014; 2016). The findings reveal that Thai taxi drivers, as stakeholders in the growth of the Thai economy, have a lower level of English competence and they experience three cross-cultural communication challenges in language, cultural, and attitudinal domains. Effort to improve their English skills needs to take into consideration the nature of their work and their work conditions.
\end{abstract}

Keywords: cross-cultural communication, Thai taxi drivers, economic growth.

\section{Introduction}

Thailand has engaged the world in every front, economically, culturally, and politically, there have been more and more foreigners and visitors from near and afar alike visiting the kingdom, some are from the Western world; others are from neighboring countries and the rest of the world. When they come to visit or work in Thailand, they need to take public transportation such as trains, buses, and, of course, taxi cabs. What they have to manage is using English with Thai service providers, including the taxi drivers. The obvious problem is communication, as English is still considered a foreign language in Thailand, and not many taxi cab drivers are well-equipped with English. In many senses, it can be said that Thai taxi cab drivers are working at the frontier of this globalization process and they are stake-holders in the development of the Thai economy. Their ability to provide quality services is thus crucial for national development. This also requires their ability to communicate cross-culturally.

Cross-cultural communication occurs between at least two cultural groups or individuals. When Thai taxi drivers are requested by non-Thai customers and when the customers do not know Thai, communication challenges may occur. Previous research suggests that Thai taxi drivers lack adequate English language skills, which could hinder successful cross-cultural communication.

Language is a part of culture and cultural elements are abundant in language use. Any attempt to teach English to Thai taxi drivers cannot overlook the cultural dimension. As Thailand is integrating into the ASEAN community, the demand for English instruction for taxi drivers is on the rise, but the supply side of the equation is far from adequate. Moreover, the instruction approach and the contents often lack the true understanding of the ways taxi cab drivers use English, not to mention the lesser emphasis on culture. Furthermore, their unique background and needs are often overlooked. What has been done is instructing them using a conventional approach. Considering their workload and the nature of their work, putting them into a conventional program may not be very helpful (Thadphoothon, 2014).

This research investigates the cross-cultural communication problems and challenges among Thai taxi drivers. 


\section{Literature Review}

\subsection{Thai Taxi Drivers and Their Work}

In the Thai context, whenever one hears the word 'taxi driver', one often attaches some qualities into it, almost instantly. Such attitudes vary, some positive, some negative, depending on one's personal experience and background. Travelling by taxis involve elements of risks. $47 \%$ of the people in Bangkok were not confident in the safety of taxis (ABAC Poll 2005, quoted in Seesan, Runkasiri, and Cooharojananone, 2012). At the same time, the same poll found that travelling by taxis is the most convenient type of transport. It must be admitted that Thai taxi drivers are among the most neglected workers in Thai society, despite being a part of the 'stakeholders' for the growth of the Thai economy and other developmental ambitions. Little research has been done to look closely into their lives, plights, challenges, and opportunities.

Thai taxi cab drivers are a part of Thailand's social fabric. Yet, they are often neglected by Thai society when it comes to education, despite the country's strong need to be internationalized. Indeed, they have language problems, especially English (Thadphoothon, 2014). This has been recognized by many visitors. Many websites recommend visitors to Thailand to learn to speak some Thai. This may show that Thai taxi cab drivers have problems communicating in English. For example, http://www.into-asia.com/bangkok/taxi/problems.php (last accessed 15 December 2016) suggests people to learn some Thai: "The best way to avoid any problems is to speak some Thai. This may seem difficult, but the level required for taking a taxi is quite simple."

The public's view of Thai taxi drivers varies. From the media, they are not always perceived positively either. Many people complain that some drivers reject their requests and some are picky when it comes to destinations. For example, if where the passenger wants to go is too far or when the traffic is jammed, some taxis decline to provide the service. Many visitors get upset when they are declined by the taxicab drivers. One website, for example, claims that The Bangkok Post has conducted research on reasons or rather excuses for not picking up passengers. Among the cited reasons included the need to return the car to the garage or the car needs refueling. Some taxi drivers prefer accepting only foreign passengers. These types of taxis are found near tourist areas. Many usually do not turn on their meters and charge excessive fare.

Indeed, taxi drivers have received many complaints. The Department of Land Transport reported that there were almost 6000 complaints within the first three months of the year 2012. Of that number, over 3000 taxi cab drivers were fined or disciplined.

There have been complaints on safety. Even though there are rules and regulations prescribed by the authorities regarding traffic laws and the regulations from the Department of Land Transport, it is not always the case to find a driver with good character and good manners. Every now and then the public would hear some usual complaints on the taxi services, e.g. the driver behaved very immorally, the price is too high, or some were driving carelessly. Many of them need some training on, not only communication, but safe driving. The authority and the public are aware of the problems. But the truth is that it is not practical to train a large number of taxi drivers, and it is not feasible to set the entry standards up high to screen only desirable taxi drivers. The reality is that any Thai citizen, male or female, can become a taxi driver with minimum educational requirements and a public vehicle driving license.

On the positive aspect, Thai taxis were rated among the best in the world. Hotels.com revealed the website survey of taxi services worldwide. It indicated that taxis in Bangkok were among the best in the world in terms of values for money and services. Thailand was voted as one of the 10 best taxi service in the world. The surveys were conducted in more than 30 countries and 28 cities around the world. Bangkok ranked eighth in an annual survey, and received an honorable mention as the city 
with the best value tariffs by taxis. The ranking was based on the travelers votes from seven special features include friendliness, knowledge, cleanliness, safety, and quality of driving.

Thai taxi drivers work long hours on busy streets and narrow alleys of Bangkok. It is time to really regard taxi cabs as safe and efficient public transport. They have to work under harsh conditions with limited English skills and few training opportunities.

\subsection{Attitudes and Motivation}

Thadphoothon (2014) reports some glimpses of the effects of Thai taxi drivers' attitudes toward foreign passengers. Those attitudes seem to influence their willingness to communicate and associate with the individuals. In language studies, some studies found that, in an ESL setting, attitudes affect second language acquisition (Oller, Hudson, and Liu, 1977). However, some studies did not find a relationship between the two variables (e.g. Cooper and Fishman, 1977). Traditionally, attitudes are hypothesized to entail one dimension, affective. Bostrom (1970) conceptualizes attitudes as having three separate dimensions: behavioral, cognitive, and affective.

Motivation is conceptualized has having two related factors: integrative and instrumental (Gardner and Lambert, 1972). Instrumental motivation refers to a desire to engage in a learning activity because of its utilitarian goals; integrative motivation refers to a desire to identify oneself with a particular cultural group. Integrative motivation was found to affect learners' language proficiency (Spolsky, 1969).

\subsection{Language, Communication, and Culture}

Language is the human capacity, some argue, for acquiring and using complex systems of signs and symbols. In a broader sense, language is a part of culture. However, language is not only a tool it is also part of culture. It is embedded with values and assumptions. Benjamin Lee Whorf has hypothesized the link between language and culture. Communication is not simply an exchange of data or information; it is also an interaction of two or more cultures. Communication may or may not rely on text or verbal elements of language. For example, facial expressions can communicate feelings and emotions. Touching is another element of communication that requires no explicit language forms. Communication, verbal or non-verbal, is to a great extent, influenced by culture.

\subsection{Previous Studies on Thai Taxi Cab Drivers}

There is little research on Thai taxi drivers' English use and its characteristics, and their cross-cultural communication challenges. Mittanonsakul (2010) investigated the attitudes of Thai taxi drivers toward passengers with disabilities. 100 taxi drivers in the Bangkok metropolis were sampled to answer the questionnaires. It was found that the taxi drivers had moderate attitudes towards the disabled persons. The research recommended that relevant authorities provide training programs to help Thai taxi drivers provide better service to people with special needs. Salathong (2011) conducted a study investigating the quality of life of Thai taxi drivers. He found that most of them did not receive any on-the-job training. Their job security and safety were low. Taxi drivers would like to receive support from the authority to develop their career and the service quality.

\section{Method}

Both qualitative and quantitative data were used to address the issues of Thai taxi drivers' cross-cultural communication problems and challenges. The article draws on the findings from two related studies (Thadphoothon, 2014; 2016).

Study I --- Both qualitative and quantitative data were collected by 85 undergraduate students taking a course Introduction to Cross Cultural Communication (EN 238). They worked in pairs and interviewed 42 taxi drivers. The project commenced in September 2013 and lasted until the end of November 2013. As part of their project assignments, they were tasked to investigate the taxi drivers' 
language and cultural challenges through interviews. Their interview questions are within the given framework. The Thai scripts were translated into English and they gave an oral presentation of their investigations. At the end of the project, the students were asked to answer the questionnaires on their learning experience. This study relies on the interviews of taxi drivers reported by the students. The interview was done in Bangkok and Nonthaburi province. The students interviewed the taxi drivers in action. They worked in pairs and got in a taxi and asked permission to conduct an interview. They explained that the interview is part of a project on cross-cultural communication. The interview questions are within the scope of cross-cultural communication. The questions address the topics of their driving experience, English skills, attitudes, and cultural awareness. The text data was analyzed using simple content analysis. The taxi drivers' answers were categorized to identify their driving experience, attitudes towards foreign passengers, English ability, and communication problems.

Study 2 --- This study investigates Thai taxi drivers' English language competence. 342 students were randomly selected, based on two criteria: (1) the zones as classified by the Bangkok Metropolitan Authority (central, inner, and outer zones) and the taxi types as classified by the Department of Land Transport (cooperative and privately-owned), They were asked to answer the questionnaires on their basic work conditions, attitudes, toward the foreign passengers, and motivation to learn English. Each sampled taxi driver was also asked to evaluate their own English competence and performed language tasks. Their self-evaluation was correlated with their actual performance. The study began in February 2015 and completed in December 21, 2016. Data was analyzed by descriptive and inferential statistics.

\section{Findings and Discussions}

Most taxi drivers are male. In Study 2, the figure is as high as 97 per cent; in Study $1100 \%$. It was found that the majority of 384 taxi drivers had poor English language skills. In Study 1, the language they produced shows that their level of competence was generally low. Similarly, Study 2 shows that their self-assessment of the overall English skills was 2.04 with the standard deviation (SD) of .840. Language is undeniably their first daunting problem. In terms of motivation, both studies found that the majority of the taxi drivers recognize the importance of English and would like to improve their language skills. Both studies also note the significance of attitudes.

\section{Results of Study 1}

It was found that all of the taxi cab drivers (42) under the study were male. This is not a surprise as it is known in Thailand that driving taxis is generally a male job. On average, they have worked as taxi cab drivers for 8.45 years. The maximum experience was 30 years, and the minimum was only 1 year. All of them (100\%) said they have experienced servicing non-Thai customers, and those non-Thai passengers were both native and non-native speakers of the English language. Most reported that they had had communication problems when they talked to their non-Thai customers.

Most reported that they had problems when they communicated with foreign passengers. The problems included the use of English. They admitted having low English proficiency. Some reported having problems understanding the behavior of some passengers, for example, their attitudes towards feet and showing feet in the car, as well as their perceptions of body odor. As for their ways of dealing with those problems, they reported that some foreign passengers could say some Thai words, and that was helpful. Many passengers carried with them either maps or name cards, and it was proven to be helpful. The gravest problem arose when they had to solve the immediate problems and had to communicate in English with the passenger in question. Dealing with unforeseen problems such as explaining to the need to take a shortcut or when nature calls and the need to visit the toilet, among others, are often beyond their competency level. Similar situations include the need to ask for the right direction or the exact spot when the passengers have to get out of the car. 
With regards to the characteristics of English used by the taxi cab drivers, it was found that most relied on short sentences with the frequent use of 'content words, which reflects their background. Their focus is on communication. Most of them, to some level, were successful in their communication.

The most obvious problem is their limited English language ability, which can be classified as the language barrier. They found it difficult to start a conversation or to respond to questions from the foreign customers. Their English is limited to basic functions. Based on the data analysis, it was also salient that some problems were beyond the language per se. In this study, we regarded them as the cultural-related problems. This is not an easily visible problem. In Study 1, many of them were not aware of cultural differences between Thai and Western culture. For example, when they greet they will say hey! you where you go? Which is common in Thailand but it often sounds impolite by some westerner even though the communication was successful. It would be more successful. If they say hello! Where to sir? or where to madam? Another example was when they collected the fare. Some drivers expected their foreign passengers to be more generous like giving them tips. Some drivers made a comment that some foreign passengers were 'stingy' because they did not tip them at all, and demanded the change to be exact to a cent. This may reflect the fact that some foreign passengers do not give tips in their countries. And because of the cultural differences, the drivers certainly form their own attitudes towards the foreign passengers. This latter one can be classified as the attitudinal barrier. For those attitudinal barriers, it must be noted that they are of two sides, the drivers and the passengers. Some taxi drivers expected extra money from foreign customers. They were disappointed when they got nothing apart from the fare. Many taxi drivers had the positive attitudes toward Farangs (white-skinned Caucasian Westerners), reasoning that the tips from them were good. Some taxi drivers said that some foreign passengers were rude to them. In general, however, Thai taxi drivers had a positive attitude toward foreign passengers.

\section{Results of Study 2}

Like Study 1, most taxi drivers were male (335 or $98.00 \%$ ). Only 7 of them or $2.05 \%$ were female. The majority of the taxi drivers are between 38-57 years old. The majority of the taxi drivers completed their primary and lower secondary education $(57.73 \%)$ and 201 taxi drivers $(58.77 \%)$ said they received no English language training at all. Eighty-five of them $(24.85 \%)$ said they had received only 1 training. Only 36 of them (10.53\%) had an English training once in 12 months. This table shows that the majority of Thai taxi drivers have very little English language training. The findings of Study 2 confirm those of Study 1. It was found that the English competence of Thai taxi drivers is generally low. The average mean is 1.96 (out of the highest possible of 5), which indicates that, in general, the taxi drivers assessed themselves as having weak English competence. It is noted that they rated their knowledge of other cultures as low as 1.79. It was found that the actual English performance of the taxi drivers was low too. Their ability to read aloud was low. Their oral interaction skills as measured by their ability to orally answer the questions were considered low. These measures show that their English competence was low. It was also found that the correlation between their self-assessment and actual performance was significantly correlated. The significant correlation among the sub-components of the Test of Thai Taxi Drivers' English Competence is found at the level .01.

The correlation between the self-assessment and the test performance is high and significant at the 0.01 level of confidence $(r=0.514)$. The correlation between their integrative motivation to learn English (INMO) and their instrumental motivation (TOMO) is significant at the 0.01 level of confidence $(\mathrm{r} .=.789)$. Their instrumental motivation is related to their attitudes and English competence. It was also found that the taxi drivers' English competence is significantly related to their education attainment. 


\section{Discussions}

Problems of Thai Taxi Drivers --- Their low ability and skills to communicate in English is one of the biggest problems. The two studies reveal their humble English competence. Their English competence is found to be significantly correlated with their education. Many Thai taxi drivers only have basic primary education. It is not a surprise to discover that their English language competence is still at the lower level. However, there are taxi drivers who are competent in English and have higher levels of education. This reflects the fact that taxi driving is an open career and opens to all Thais who qualify by law to earn a living by driving taxis.

Training Opportunities --- The findings confirm the previous research conducted Salathong (2011) which reported that taxi drivers receive very few training opportunities. Despite the growing number of projects aiming to develop their services and language skills, Thai taxi drivers in general still need more training. In Study 1, of the 42 taxi drivers surveyed, only $22 \%$ of them (9) said their English was sufficient or adequate to cope with the demand of English. The majority of them $(78 \%$ or 33 taxi drivers) said that their English was poor or very poor. It is not a surprise that all of them said that they would like to improve their English. However, the kind of English language they preferred learning is for communication, not examination.

Communication and Grammar --- This study found that English language used by the taxi drivers is limited to the basic level and the taxi drivers focus mainly on communication, not style or grammatical accuracy. The taxi drivers' English shows us that their focus was on communication. Indeed, one characteristic of their English reveals that the L1 transfer, especially the use of pronoun 'You'. What is salient is also in the pronunciation, which is also another example of L1 transfer. In Study 1, it was found that the language use of the taxi drivers follows the stages prescribed by the order of L2 development (Vainikka and Young-Scholten, 1991). Even though the data in this study is far from conclusive, the presence of the bare VP-stage, e.g. You go where?, signifies their language developmental stage. Our examples also reveal the possibility that the user may transfer his existing world knowledge into their L2 use. One example, in particular, "You money highway" was given by one taxi driver. He said it worked well, but his explanation gave us more insight into the rationale of his use. The user explained that the word 'you' was used to refer to his interlocutor, not him. The word money placed right after the word you means that it has to be the other party's money. The word 'highway' is what is better known in Thailand than the word 'express way.'

Culture and Attitude --- In Study 1, many taxi drivers expressed their personal opinion towards different groups of foreign passengers, and one of the reasons behind the attitude seems to be the tips from the foreign passengers. This, if anything, should point to the relationship between cultural differences and their potentials to form or create certain attitudes. Some taxi cab drivers said they found the use of feet of some passengers unacceptable and rude. This reveals the significant difference between Thai and the general western cultures. In many western cultures, the show of feet is not an offence and there is no offence in the use of feet. Most Thais, however, regard feet as something low and they should not be shown in public.

Study 2 reveals that the taxi driver's attitudes toward foreign passengers are either moderate or slightly high $(\mathrm{M}=3.50)$, while their self-assessment of their own knowledge of other cultures is low $(\mathrm{M}=1.79)$. We also found that significant relationship between their cultural knowledge and English language skills.

Language \& Cultural Barriers --- As reported, the taxi drivers experienced communication difficulties when they provided services to foreign passengers. However, it was discovered that most Thai taxi drivers experienced not only language, but cultural difficulties. The use of 'you' as a personal pronoun seems to be the most common expression to address a foreign passenger. They 
expression "You, you pay money highway" may be effective in many occasions. It, however, may create misunderstanding, as some may regard it as being insensitive. From the understanding of the taxi drivers, the word 'you' is polite as it means 'khun' in Thai. This, if anything, indicates the link between language and culture.

In Study 1, many taxi drivers also mentioned the behavior of some foreign passengers to be 'rude'. Those mentioned behaviors were: (1) putting up their feet in the car and (2) being stingy (not giving tips). As language is part of culture, any effort to help develop the drivers' English needs to address the issues related to culture, such as addressing terms, the culture of tips, taboos, and time orientation.

English Competence and Attitudes --- The taxi drivers' English competence is significantly related to their behavioral-orientation attitudes toward the foreign passengers $(r=0.133)$. Only their behaviorally-focused attitudes were found to be significantly related to their English language competence. Three characteristics of the taxi drivers, enjoying listening to English songs, perceiving the imported products positively, and willingness to provide services to foreign passengers, are positively related to their English language performance.

Heavy Workload and Time to Relax --- The two studies point to one common problem among Thai taxi drivers, that is, their workload imposed by the need to earn enough money to pay the rent, the gas, and their basic necessities. This leads to stress and poor health. In Study 2, the majority of them spent between 70-90 hours working per week, on average 8-10 hours per day. It was found also that 197 $(57.60 \%)$ said they did not have any day off in a week and one-third of them had only one rest day per week. This is a challenge when it comes to self-development for better quality of life such as cross-cultural communication training. With heavy workload and little time to rest and relax, the majority of Thai taxi drivers simply do not have free time to improve their English competent, even when they are aware of its importance.

\section{Conclusions}

The two studies reveal that Thai taxi drivers have problems and challenges in cross-cultural communication in three areas: English language, culture, and attitudes. Both studies document their problems and challenges arising from the need to communicate cross-culturally. Considering the fact that as high as $70 \%$ of them have to encounter foreign customers per day and their role driving the Thai economy, it is essential that they are equipped with language and cross-cultural communication skills.

\section{References}

[1] Bostrom, R. N. (1970), Affective, Cognitive, and Behavioral Dimensions of Communicative Attitudes. Journal of Communication, 20: 359-369.

[2] Cooper, R. and Fishman, J. (1977). A study of language attitudes. In Fishman, R., Cooper, J., and Conrad, A. (eds.) The Spread of English: The sociology of English as an additional language, pp. 239-76. Newbury House, Rowley, Mass.

[3] Department of Land Transport of Thailand "Taxi Service Manual" Available online at http://www.dlt.go.th/th/sara/article/texi\%20meter_userguide.htm [Last accessed March 15, 2015]

[4] Department of Land Transport of Thailand "News of the Department of Land Transport" DLT News” No. 83 May 3rd, 2012. Available at www.dlt.go.th [Last accessed 15 March 2014]

[5] Gardner, R.C. \& Lambert, W.E. (1972). Motivational variables in second language acquisition. In R.C. Gardner \& W. Lambert (eds.) Attitudes and motivation in second language learning. (pp. 119-216). Rowley, MA: Newbury House. 
[6] Mittanonsakul, K. (2010) “Taxi drivers' attitudes towards disabled persons” in Rachasuda College for Research and Development of Persons with Disabilities. 6(2)

[7] Oller, J., Hudson, A and Liu, p. (1977). Attitudes and attained proficiency in ESL: sociolinguistic study of native speakers of Chinese in the United States. Language Learning. 27: 1-27.

[8] Salathong, P. (2011) “Measures to Improve the Quality of Life of Taxi Drivers" Available on tine (inThai) https://repository.rmutp.ac.th/bitstream/handle/123456789/1348/Larts_56_02.pdf?sequence=1

[9] Seesan, R., Runkasiri, T., Cooharojananone, N. (2012) "Taxi Friend: Innovative Application for Thai Passengers" Paper presented at International Conference: Innovative Research in a Changing and Challenging World, 16-18 May 2012, Phuket, Thailand. Retrieved on December 22, 2016 from http://www.auamii.com/proceedings_phuket_2012/ramanaseesan.pdf

[10] Spolsky, B. (1969). Attitudinal aspects of second language learning. Language Learning, 19 271-85.

[11] "Tips to avoid problems with taxi drivers" From

http://www.nationmultimedia.com/national/Tips-to-avoid-problems-with-taxi-drivers-30205641.ht $\mathrm{ml}$ [13 December 2013]

[12] Thadphoothon, J. (2014). Report on a classroom project to investigate problems and characteristics of English language as used by Thai taxi drivers.

Dhurakij Pundit University. (Unpublished Report)

Available online at http://libdoc.dpu.ac.th/research/154734.pdf

[13] Thadphoothon, J. (2016). Factors Affecting Thai Taxi Drivers English Competence. Dhurakij Pundit University (Unpublished Report)

[14] Thai Taxis Go Inter from

http://www.trs995.com/event-project-detail.php?id=6\#.WFOv6zuLTy0 [Last accessed 16 December 2016]

[15] Vainikka, A., \& Young-Scholten (1991). Verb raising in second language acquisition: The early stages. Theories des Lexicons, 4. 1-48. 